\title{
Cultura literaria en dos niveles de español (A2 y B1)
}

\author{
ELIA SANELEUTERIO \\ Universitat de València \\ elia.saneleuterio@uv.es \\ JAUME BRINES \\ Centre d'Idiomes - Universitat de València \\ jaubri@alumni.uv.es
}

\section{Resumen}

Presentamos una experiencia de acercamiento de estudiantes de E/LE a la cultura española mediante su poesía, para tratar aspectos de la literatura relevantes en el aprendizaje de la lengua, tales como la dicción, las rimas, el léxico y algunas figuras literarias, seleccionando algunos hitos de la tradición poética española que pusieran al estudiante en contacto con esta parte de nuestra cultura.

El diseño pretendía atraer la atención, fomentar un contexto de aprendizaje distendido y despertar el gusto estético; estos objetivos van de la mano del género literario trabajado, dado que la poesía es la gran excluida en las clases de español como lengua extranjera.

La comprensión oral y la lectora jugaron un papel relevante en cuanto a competencias se refiere, enfatizando al mismo tiempo en la recitación de los poemas y en la expresión oral.

Las actividad se llevó a cabo con estudiantes Erasmus del Centre d'Idiomes de la Universitat de València, con dos grupos de niveles A2 y B1, respectivamente.

Palabras clave: poesía, E/LE, cultura, lengua

\begin{abstract}
This practical experience wanted to approach Spanish L2 students to the Spanish culture through its poetry, in order to treat some relevant aspects of the literature in the language learning, as diction, rimes, vocabulary and some rethorical device, choosing some landmarks of the poetical Spanish tradition to bring closer each student to our culture.

The design tried to attract the attention, furthering a relaxed learning context and inciting the aesthetical pleasure; these aims go together with the literary worked gender, as poetry is one of main forgotten genders in Spanish L2.

Oral and reading comprehension played an important role as competences, emphasizing as well in poems recitation and oral expression.

The activity was carried out in two groups of Eramus students (A2 and B1 levels) at the Centre d'Idiomes of the Universitat de València.
\end{abstract}

Keywords: poetry, SFL, culture, language 


\section{1. ¿Por qué la poesía en clase de E/LE?}

Uno de los aspectos que hace recomendable exceder el nivel puramente lingüístico en la enseñanza de lenguas es su efecto en la motivación, el aumento de interés y la mejora de las actitudes que hacia ellas muestran los estudiantes durante el proceso de adquisición (Janés, 2006). Así, en la práctica van recuperándose las teorías y las prácticas docentes que abogan por la incorporación de experiencias literarias en la lengua que se aprende (Álvarez, 2004; Labrador y Morote, 2007; Saneleuterio, 2008; Saneleuterio y Prats, 2016), hasta el punto de asumirse que es necesario revalorizar el potencial que presenta la literatura en la creación de contextos comunicativos significativos y motivadores para ejercitar las diferentes destrezas (Albadalejo, 2007: 2). En definitiva, se trata de no despreciar estos «textos lo suficientemente cargados y sugestivos como para que actúen como mediadores y provocadores de ese proceso de negociación e intercambio creativo impredecible que es la comunicación, y al que, tarde o temprano, tendrán que enfrentarse los aprendices de una lengua extranjera» (Acquaroni, 2006: 51).

Si nos centramos en la poesía, esta suele aglutinar algunos de los hitos más importantes en la literatura de cualquier lengua y, como tal, llega a suponer una de sus representaciones culturales más destacadas. Respecto de la poesía en lengua española, contamos con una larga tradición, representada por innumerables autores, estilos y temáticas, tanto en el continente europeo como en el americano. Considerando la conveniencia de prever mecanismos de identificación lengua-cultura-país, en nuestro caso es comprensible que nos interese, ante todo, la poesía peninsular, dado el contexto educativo de nuestros estudiantes, en su mayoría estudiantes internacionales más o menos recién llegados al este de España, si bien, la tradición poética hispanoamericana también podría utilizarse como refuerzo y, por qué no, para ver algunas diferencias o similitudes entre ambos continentes.

Cabe señalar que, casualmente, este género, junto con otros que se vienen reivindicando recientemente, como el cómic (Rivera, 2016), es uno de los grandes excluidos en E/LE; aunque siempre hay excepciones (Sáez, 2011), su presencia en las clases es frecuente que pase desapercibida o ni aparezca (Ferreira, 2012). Esto queda patente no solo en los manuales de español, sino también en los programas de aprendizaje del español como lengua extranjera (Martín, 2000). La poesía es, sin duda, el género literario que menos presencia tiene y del que, por lo general, solo se ven algunas trazas en niveles superiores, como B2 y $\mathrm{C} 1$.

Finalmente, como se recoge en Saneleuterio (2008: 330), los poemas ofrecen algunas características que los convierten en elementos perfectamente acoplables a las sesiones de E/LE, como por ejemplo el hecho de que podemos encontrar muchísimos textos breves, cuya principal ventaja consiste en resultar abordables en una sola sesión. Asimismo, además de que las licencias e imágenes permiten un acercamiento sugerente al lenguaje metafórico, figurativo y connotativo de la lengua española, no es despreciable el hecho de que una buena selección poética puede ofrecer un panorama interesante de gran parte de la literatura española.

Con la sesión que presentamos, y a pesar de conformar una experiencia poética aislada respecto de la totalidad del curso, se pretendió compensar esta ausencia en la clase a través de unas dinámicas que acercasen este género a los aprendientes de $\mathrm{E} / \mathrm{LE}$, lo que en definitiva implica una aproximación a parte de la cultura de España. 


\section{Objetivos y metodología}

Los cuatro objetivos fundamentales que se plantearon en el diseño de la sesión fueron los siguientes: atraer la atención del estudiante por la poesía; fomentar un contexto de aprendizaje distendido; despertar el gusto estético; acercar a la cultura española y a ciertos usos de la lengua.

Basándonos en una adaptación de los modelos de Maldonado (1997) y Arlandis (2007), el diseño pedagógico de la actividad giró en torno a la selección de textos adecuados para ambos niveles, A2 y B1, donde se plantearon cuatro ejercicios suscitados por varios poemas y con los que se conseguiría la activación de las siguientes destrezas:

1) Poema «Cuando yo me muera», de Federico García Lorca: lectura y pronunciación de fonemas complicados para hablantes no nativos.

2) Rima XLII de Gustavo Adolfo Bécquer: discusión de impresiones poéticas mediante la interacción oral.

3) «Sol de invierno», de Antonio Machado y fragmento de «Ándeme yo caliente/y ríase la gente», de Góngora: léxico relacionado con el invierno en España.

4) Breve biodata de Antonio Machado: diálogo en trabajo por pares mediante ejercicio dual por huecos.

Cada ejercicio pretendía a su vez la consecución de diversos fines, entre los que destacamos que, en el primero, la lectura en voz alta sirvió para practicar fonemas de difícil articulación para la mayoría de los estudiantes extranjeros. Cada estudiante recitó un par de versos, dinámica que ayudó a muchos a concienciarse de la dificultad para pronunciar dicho fonema, cuya práctica en el aula agradecieron. Además esa repetición fonética sirvió para que los aprendientes se percataran del ritmo que Lorca imprimió a este poema como fuente de placer (Peragón, 2014).

Respecto a la rima de Bécquer, tenía como fin inducirles a explorar su significado implícito y, para ello, debían interpretar en parejas qué sucedía e inventar una historia en torno a la anécdota no dicha: se trataba por lo tanto de trabajar la expresión oral partiendo de las impresiones poéticas que producía la lectura del poema.

La finalidad de la última actividad era tratar, mediante un ejercicio dual, la biografía de una de las figuras más representativas de la poesía española, como es Antonio Machado. Se trataba de que cada estudiante completara los huecos de su texto preguntándose, recíprocamente por parejas, la información omitida que sí tenía la otra persona.

Como metodología de investigación, se completó el feedback observado en el aula con la respuesta a un cuestionario virtual que midiera, entre otros aspectos, el grado de satisfacción del alumnado acerca de la actividad.

\section{Contextualización: características de los estudiantes}

El diseño se puso en práctica en el Centre d'Idiomes de la Universitat de València, con dos grupos de estudiantes de E/LE (A2 y B1), con edades comprendidas entre los 21 y 27 años, todos europeos excepto una alumna surcoreana. La mayoría eran estudiantes internacionales o de intercambio Erasmus, salvo un profesional y un doctorando.

Frente a la heterogeneidad del grupo de A2, donde nadie coincidía en lengua materna, 
desde el punto de vista del origen y de las lenguas de los participantes el grupo de B1 ofrecía unas características más homogéneas, siendo la mitad de los participantes de lengua alemana, más dos italianas, una surcoreana, un polaco y un ruso.

Finalmente, cabe señalar la poca predisposición que, en general, la muestra tenía hacia la poesía antes de la actividad. Esto suele ser bastante común, por lo que, como demuestra Coloma (2011), es la actitud del profesor y el interés de la propuesta lo que puede garantizar el éxito y la atención de los estudiantes.

\section{Desarrollo de las sesiones}

Las sesiones tuvieron lugar en enero de 2017. Al hacerse en época de exámenes universitarios, la afluencia a ambas sesiones fue bastante escasa respecto al número de estudiantes matriculados. Para despertar el interés de los aprendientes por un género poco visto durante las clases de E/LE y, a priori, relativamente desconocido para la mayoría de estos, se intentó, a través los grandes temas de la literatura, tan fructíferos en la enseñanza de segundas lenguas (Acquaroni, 2007), conectar con la universalidad de las preocupaciones humanas, pero asociándolas con la particularidad de la vivencia española a partir de algunos elementos emblemáticos de la vida y costumbres: el sol, la guitarra, el brasero, los inviernos suaves... Todo ello nos permitió observar las impresiones que los estudiantes tenían en torno a la puesta en marcha de la actividad.

Para ello, se llevaron a cabo diversas estrategias como la lectura compartida, en la que todos los aprendientes recitaron el poema de Lorca y se observaron las dificultades de pronunciación del fonema vibrante múltiple. Para crear un ambiente distendido, los profesores fueron animando a cada uno de los alumnos con el fin de lograr una buena entonación a través de la escenificación/dramatización de los mismos. Con ello se logró inicialmente un ambiente distendido: se trabajó el abandono de la vergüenza para conseguir lecturas mejor recitadas. Esta parte desinhibidora fue también enfatizada con la lectura del primer poema por parte de los profesores, a través del uso del cuerpo en la recitación y la exageración de fonemas y sonidos. Esto motivó que en las posteriores lecturas de los siguientes poemas, los alumnos imitaran dicha manera de recitar las poesías y con ello se reforzara la parte lúdica de la actividad: de este modo los más extrovertidos dieron rienda suelta a su faceta interpretativa.

Por otra parte, la comprensión lectora fue concebida como motivadora, puesto que al trabajar la rima LXII de Bécquer en parejas, debían llevar a cabo la construcción conjunta de significados. Así, además de ponerse de acuerdo para ofrecer al resto de la clase una interpretación tras haber discutido entre ellos mediante un diálogo inter pares, la aclaración de vocabulario permitió una mayor comprensión de los poemas y la discusión sobre significados implícitos.

Finalmente, el diálogo entre iguales también resultó una estrategia fructífera en la actividad dual sobre la biografía de Antonio Machado, que requería una dinámica de preguntas y respuestas orales, con petición de aclaraciones e, incluso, deletreos.

\section{Resultados de las sesiones}

Durante las sesiones, algunos estudiantes mostraron distanciamiento y cierto pudor a la hora de interpretar y recitar los poemas, mientras que otros jugaron su rol a la perfección 
como si de una performance se tratara, cosa que resultó motivadora. En cuanto la recitación poética, las aliteraciones de Lorca resaltaron la dificultad que comporta la pronunciación del fonema $/ \mathrm{rr} /$ incluso por parte de estudiantes que no deberían tener problema por existir también en su lengua materna, como es el caso de los italianos. Este fonema fue pronunciado con dificultad por el resto de estudiantes de B1, excepto los de nacionalidad polaca, rusa, austríaca y alemana. En el grupo de A2, tan solo el estudiante italiano, que además mostró gran motivación por la actividad, fue capaz de pronunciar bien este fonema. Otro de los fonemas que también se practicó fue el de la jota española $(/ \mathrm{X} /)$, por ejemplo en la palabra «naranjos», especialmente difícil para algunas alumnas alemanas e italianas.

En la rima XLII de Bécquer, los resultados fueron sorprendentes en ambos grupos. Al leer la rima en parejas, los aprendientes debían imaginar qué había podido pasar para que el hablante lírico sintiera tanta rabia como transmite en el poema. A priori, cualquier hispanohablante, tras la lectura de la rima, pensaría que el autor había experimentado una infidelidad amorosa. La mayoría de estudiantes, tras debatir en parejas la causa de la tristeza del poema, se acercaron a esta interpretación de infidelidad con conceptos como melancolía, tristeza, muerte de un ser querido, desamor, dolor, celos, que ciertamente pueden guardar similitudes con lo que se siente ante la traición de un ser querido, pero nadie fue capaz de nombrar los conceptos infidelidad o traición. Esto llamó mucho la atención de los profesores, pues estos pensaban que la primera interpretación sería la de una infidelidad. Ello se explica por el hecho de no dominar por completo la lengua castellana, junto con la falta de referencias para algunos conceptos culturales que pueden guardar implicaturas respecto a la infidelidad, tales como:

$$
\begin{aligned}
& \text { Cuando me lo contaron sentí el frío } \\
& \text { de una hoja de acero en las entrañas, } \\
& \text { (...) } \\
& \text { Cayó sobre mi espíritu la noche } \\
& \text { en ira y en piedad se anegó el alma } \\
& \text { iy entonces comprendí por qué se llora } \\
& \text { y entonces comprendí por qué se mata! }
\end{aligned}
$$

Aparte de este dato curioso, la interpretación más graciosa del poema corrió a cargo del alumno ruso de B1, quien dijo que el autor se había enterado de la victoria de Donald Trump en las elecciones de los EE.UU. (noviembre de 2016) y que por eso estaba tan consternado. Ciertamente, el poema podría acoplarse a muchas interpretaciones consideradas negativas por parte del lector, y en ello residía precisamente el interés de la actividad.

En cuanto a los poemas relacionados con el invierno, léxicamente se destacaron: brasero, castañas, blanca nieve, enero, Blancas sendas y ramas esqueléticas. Así, los estudiantes relacionaron la presencia de las castañas con el invierno, así como la nieve, el frío y las esqueléticas ramas ( $\sin$ hojas durante la época invernal). Esto de alguna manera demostró que los fríos inviernos que Góngora y Machado padecieron en el interior de la meseta (Madrid y Soria), con frío seco y continental, se asemejaban a los que la mayoría de alumnos ha experimentado en sus propios países. En ese sentido y pese a que el frío de países como Alemania, Polonia o Rusia son mucho mayores que en España y sus idiomas 
deben de tener una gran variedad de expresiones y conceptos referidos al helor de esa estación, los estudiantes de ambos grupos comprendieron y asimilaron el significado de ambos poemas.

Curiosa fue, cuando menos, la explicación de brasero. Las estudiantes alemanas no entendían para qué servía un objeto semejante y tuvo que ser el estudiante austríaco el que se lo explicara. Aun así seguían sin comprenderlo. Quizás esto debió de ocurrir por ser Austria un país más tradicional y, en cierto modo, más rural que Alemania, donde posiblemente los braseros hayan desaparecido completamente de los hogares hace décadas, mientras que en Austria en algunos aún sea posible encontrarlos.

Finalmente, el análisis del ejercicio dual referido a la biografía de Machado ofrece algunos resultados en cuanto a errores gramaticales y ortográficos en lo que a expresión escrita se refiere. Así, fue posible observar cómo había errores tales como:

- Omisiones de sintagmas: "Estos días azules" (...y este sol de la infancia).

- Omisiones de obras: Galerías, Otros poemas, Campos de Castilla.

- Ortográficos y de comprensión oral: "Soledad" o "Solledades" (por Soledades).

- Errónea comprensión oral: “1926” por "1927”, "Camposte” por “Campos de”.

- Errores de acentuación: "catedratico", frances".

- Errores de mayúsculas: "real academia".

- Errores de género: "Español” por "Española".

Dado que el estudiante que tenía en cada caso la información disponía de ella por escrito, de estos errores se deduce que en el dictado de palabras persisten problemas de pronunciación, comunicación, comprensión oral y ortografía.

\section{Resultados del cuestionario}

Tras las sesiones, los docentes prepararon una serie de preguntas en un cuestionario vía Googledrive. En él, se pretendía recoger las consideraciones del alumnado con respecto a la experiencia poética vivida en ambos grupos. Solo 10 estudiantes completaron la encuesta, hecho que nos hace pensar que, pese a ser virtual, habría sido mejor que los estudiantes no la respondiesen en casa, sino en el aula.

Las preguntas, distribuidas en 5 bloques, se transcriben en la figura 1.

Bloque 1: Datos (nombre, edad, sexo, estudios, país de procedencia y lengua/s materna/s)

Bloque 2: La poesía y yo

- $\quad$ Me gusta la poesía (1 a 5)

- $\quad$ Suelo leer poesía en mi lengua materna (1 a 5)

- $\quad \mathrm{Mi} / \mathrm{s}$ poeta/s favorito/s es/son

\section{Bloque 3: Poesía en español}

- $\quad$ Antes de enero, ¿habías oído algún poema en español?

- $\quad$ En caso afirmativo, ¿habías trabajado poemas en alguna clase de español?

- $\quad$ ¿En qué nivel? 
- $\quad$ Indica el nombre de algún autor o autora de aquellas actividades de poesía en E/LE

Bloque 4: La poesía y la cultura en clase

- $\quad$ Me gustaría hacer más actividades relacionadas con la poesía en clase de español (1 a 5)

- $\quad$ Razona tu respuesta

- $\quad$ La poesía es importante para aprender la cultura de un país/lengua (1 a 5)

- $\quad$ Razona tu respuesta

\section{Bloque 5: La actividad de poesía en la clase de español}

- ¿ ¿Qué crees que has aprendido en esta sesión de poesía?

- $\quad$ Nombra los poetas que recuerdes de entre los vistos en clase

- $\quad$ Lo que más me ha gustado de la actividad es...

- $\quad$ Lo que menos me ha gustado de la actividad es...

- $\quad$ En general, me ha gustado mucho la actividad de poesía en clase (1 a 5)

- $\quad$ Recomendaría a otros estudiantes de español participar en actividades de poesía (1 a 5)

Figura 1. Cuestionario tras la experiencia

Hay que destacar que no todos los participantes respondieron a la totalidad de preguntas, siendo por ello los resultados muy dispares.

Si observamos directamente el segundo bloque de preguntas, a la de "me gusta la poesía" $40 \%$ de alumnos mostraba neutralidad en estar de acuerdo, $30 \%$ de acuerdo y otro $30 \%$ no de acuerdo.

A la pregunta "suelo leer poseía en mi lengua materna", 30\% dijo estar muy de acuerdo, mientras que el $70 \%$ restante se movía entre la neutralidad (20\%), no muy de acuerdo $(20 \%)$ y para nada de acuerdo $(30 \%)$.

Respecto a la última pregunta de este bloque, los poetas favoritos de los estudiantes que respondieron iban desde Dante Alighieri hasta Juan Pablo II, pasando por Albert Camus, Johann Wolfgang von Goethe, Victor Hugo y Paul Verlaine.

En el tercer bloque de preguntas, relativo a la poesía en español, el 70\% dijo haber oído antes de la actividad poesía en español, $10 \%$ no, y un $20 \%$ no lo sabía con seguridad. De ese $70 \%$ que sí había oído poemas, $28,6 \%$ había trabajado en clase la poesía en español, $57,1 \%$ no y $14,3 \%$ no lo sabía con seguridad. Es reseñable que todos los que sí habían trabajado con poesía en clase de español lo habían hecho en el nivel A1. Y respecto a la última pregunta de ese bloque, todos recordaban a Federico García Lorca de entre los autores trabajados en los ejercicios de poesía en clase de A1.

En el cuarto bloque, la mayoría mostró neutralidad a la hora de querer repetir actividades poéticas. En cuanto a las razones esgrimidas, encontramos las siguientes contestaciones: para mi hay cosas más interesantes, no me gusta la poesía, me gustaría conocer autores españoles, a veces, poesía puede ayudar a aprender nuevas palabras en español, porque en general no me gusta la poesía, permite aprender de una otra manera: más lúdica, es un medio de cultivarse, para mí era un poco dificil entenderlos y no lo conozco mucho.

A la afirmación La poesía es importante para aprender la cultura de un país/lengua, en general los alumnos mostraron neutralidad y estar de acuerdo puesto que algunos 
razonaron que creo que es fundamental para entender cómo se vive en un país, con muchas metáforas, la poesía se relaciona con el periodo histórico o cultural en cual estuvo escrito y creo que las cosas actuales son más importantes [sic].

Del quinto y último bloque, en relación con la primera pregunta (¿Qué crees que has aprendido en esta sesión de poesía?), los alumnos manifestaron lo siguiente: Mucho de la cultura española, He conocido unos poemas (unos casi sin rima), Antes pensaba que la poesía en otras lenguas es muy diferente, también los temas, Que los temas de los poetas de la clase eran muy similar a algunos poetas de Alemania por ejemplo, Que es más fácil leer en nuestra cabeza que en voz alta, así como el enfoque en poesía española. De los autores, tan solo dos alumnos recordaban a Góngora y a Lorca de entre los poemas que se trabajaron en el aula.

Entre las cosas que más gustaron a los aprendientes, destacan las siguientes cuestiones [sic]: La poesía, Leer en voz alta, Practicar la pronunciación y la manera en la que se lee los poetas, Intentar de entender lo que el autor escribo, Aprender la lengua a través las líneas del poema y que era la primera mirada en este tema. De entre las cosas que menos gustaron, cabe destacar Que no hemos visto muy bien los acentos (era la última lección que faltaba por ver antes del examen final), Poemas sin rima, El análisis de los poetas, El vocabulario estaba un poco dificil y la interpretación del poema también y creo que era demasiado rápido para un tema tan complicado como esto.

De las últimas preguntas, a partir de los resultados de En general, me ha gustado mucho la actividad de poesía en clase (figura 2) y Recomendaría a otros estudiantes de español participar en actividades de poesía (figura 3) se puede interpretar que la actividad de poesía en general gustó a sus participantes, a pesar de que algunos no mostrasen un gran entusiasmo en sus respuestas $(1=$ muy de acuerdo; $5=$ muy en desacuerdo).
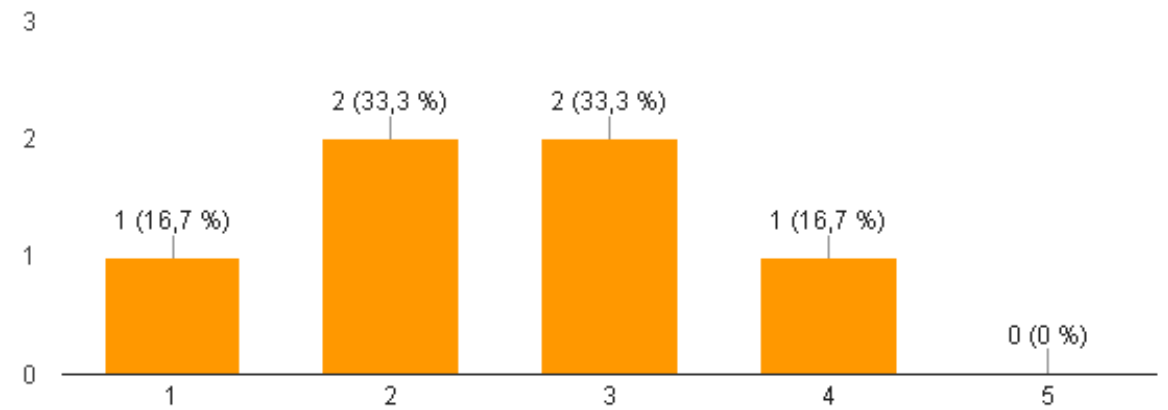

Figura 2. En general, me ha gustado mucho la actividad de poesía en clase

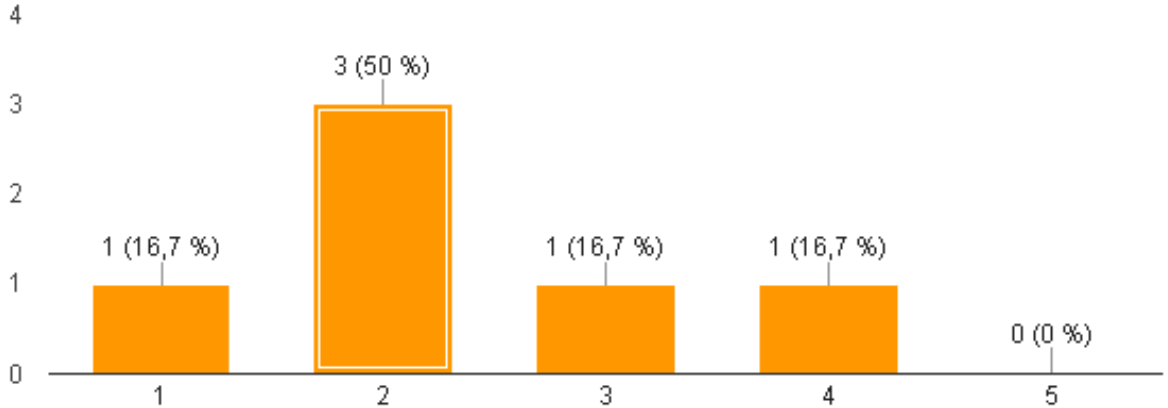

Figura 3. Recomendaría a otros estudiantes de español participar en actividades de poesía 


\section{Conclusiones}

La actividad tuvo mayor repercusión y aceptación en el grupo de B1, tal vez por el hecho de aglutinar mayor número de matriculados, así como por presentar un mayor dominio de la lengua castellana. La poca presencia de estudiantes esos días se justificó por el hecho de estar en pleno mes de enero, época de exámenes universitarios. Sin embargo, teniendo en cuenta que casi nadie manifestó especial predisposición por la poesía, podemos decir que los objetivos principales quedaron medianamente conseguidos. Así, estamos con Agustín Reyes-Torres cuando afirma:

La lectura de un texto literario, su análisis y su discusión posterior, constituyen una fuente de aprendizaje múltiple para cualquier estudiante. Además de suponer una aproximación a la representación sociocultural de una determinada época, y a las ideas de un autor, permiten pensar el mundo de nuevo. Si estas premisas las aplicamos a un curso de literatura española, o latinoamericana, para extranjeros, nos encontramos con que la literatura también representa una disciplina de un valor didáctico excepcional en la enseñanza de E/LE: el estudiante asimila la lengua a través de la obra literaria, construye distintos significados de la misma al interpretarla, y desarrolla su competencia lingüística, pragmática y cultural.

Reyes-Torres (2011: 1)

Como conclusión, creemos que la experiencia, con las limitaciones de una sola sesión, ha conseguido desarrollar en cierta medida estas competencias, como se ha demostrado, además de señalar o evidenciar puntos débiles que nos empujan a continuar la investigación-acción en este campo.

\section{Bibliografía}

ACQUARONI, R. (2006). «Hija del azar, fruto del cálculo: la poesía en el aula de E/LE». Carabela, 51, pp. 49-78.

ACQUARONI, R. (2007). Las palabras que no se lleva el viento: literatura y enseñanza de español como LE/L2. Madrid: Santillana Educación.

Albadalejo García, M. ${ }^{a}$ D. (2007). «Cómo llevar la literatura al aula de ELE: de la teoría a la práctica». MarcoELE. Revista de didáctica ELE, vol. 5, [en línea]. Recuperado el 24/4/17, de: http://marcoele.com/descargas/5/albaladejo-literaturaalaula.pdf.

ÁlVArez VAladÉs, J. (2004). «La poesía en la clase de ELE: explotaciones didácticas de un par de poemas de Carmen Martín Gaite». Red ELE. Revista Electrónica de Didáctica / Español Lengua Extranjera, vol. 0, [en línea]. Marzo. Recuperado el 24/4/17, de: http://www.mec.es/redele/revista/alvarez.shtml.

ARLANDIS, S. (2007). «Sobre la Educación Literaria: reflexiones en torno a la importancia de los clásicos en el desarrollo de la sensibilidad lectora». En Actas del I Congreso Internacional de Lengua, Cultura y Literatura Española: La Didáctica de la Enseñanza para Extranjeros. Onda: JMC, pp.493-510. Recuperado el 24/4/17, de: https://dialnet.unirioja.es/descarga/articulo/2341117.pdf.

Coloma Maestre, J. (2011). «LLos alumnos se aburren con la poesía?». Revista Foro de Profesores de E/LE, 7. Recuperado el 30/4/17, de: https://ojs.uv.es/index.php/foroele/article/view/6684/6473. 
Ferreira, M. (2012). O Texto Poético na aula de E/LE. Universidade do Porto. Recuperado el 24/4/17, de: http://repositorioaberto.up.pt/bitstream/10216/66265/2/71103.pdf.

JANÉS CARULLA, J. (2006). «Las actitudes hacia las lenguas y el aprendizaje lingüístico». Revista Interuniversitaria de Formación del Profesorado, vol. 20 (2), pp. 117-132.

LABrador PiQuer, M. J., y Morote, P. (2007). «La literatura, un recurso lingüístico en las aulas de E/LE». En Actas del I Congreso Internacional de Lengua, Cultura y Literatura Española: La Didáctica de la Enseñanza para Extranjeros. Onda: JMC, pp. 29-49. Recuperado el 24/4/17, de: https://dialnet.unirioja.es/descarga/articulo/2341054.pdf.

MaldonAdo, M. (1997). «El texto literario en la enseñanza de la lengua extranjera. Algunas consideraciones desde el enfoque constructivista». En Sánchez (ed.). Estudios de lingüistica aplicada y literatura (pp.167-173). Murcia: Universidad de Murcia.

MARTín PERIS, E. (2000). «Textos literarios y manuales de enseñanza de español como lengua extranjera». Lenguaje y Textos, 16, pp. 101-131.

PERAGÓN LóPEZ, C. E. (2014). «Hacia la búsqueda del placer estético: algunas razones para incorporar los textos poéticos en el aula de ELE». Tintas. Quaderni di letterature iberiche e iberoamericane vol. 4, pp. 53-68. Recuperado el 24/4/17, de: http://riviste.unimi.it/index.php/tintas.

Reyes-Torres, A. (2011). «Didáctica de la literatura: Textos e interpretación». Revista Foro de Profesores de E/LE, 7. Recuperado el 30/4/17, de: https://ojs.uv.es/index.php/foroele/article/view/6708/6497.

Rivera LEÓn, L. (2016). «Donde habita el olvido». Revista Foro de Profesores de E/LE, 12, pp. 209-219 Recuperado el 30/4/17, de: https://ojs.uv.es/index.php/foroele/article/view/9184/8702.

SÁEz Martínez, B. (2011). «Para un homenaje a Miguel Hernández (1910-2010) en E/LE: poesía y tecnologías educativas». Revista Foro de Profesores de E/LE, 7, pp. 239249. Recuperado el $30 / 4 / 17$ de: https://ojs.uv.es/index.php/foroele/article/view/6711/6500.

SANELEUTERIO, E. (2008). «Sensibilización poética en E/LE». Lengua, Literatura y Cultura de E/LE: Teoría y práctica docente. Onda: JMC, pp. 325-338. Recuperado el 24/4/17, de: http://goo.gl/Auhr5.

SANeleuterio, E. (2013). Versos per gaudir. Seqüències didàctiques per al primer aprenentatge de la llengua i la literatura. Madrid: EAE.

Saneleuterio, E., y Prats, J. (2016). «Taller de recitación en ELE con estudiantes vietnamitas». Revista Foro de Profesores de E/LE, 12, pp. 239-249. Recuperado el 24/4/17, de: https://ojs.uv.es/index.php/foroele/article/view/9187/8705. 